\title{
Nadir PSA is a strong predictor of treatment outcome in intermediate and high risk localized prostate cancer patients treated by definitive external beam radiotherapy and androgen deprivation
}

Fady B. Geara ${ }^{1 *}$ D, Muhammad Bulbul ${ }^{2}$, Raja B. Khauli², Therese Y. Andraos ${ }^{1}$, Mirna Abboud ${ }^{1}$, Abdelatif Al Mousa ${ }^{3}$, Nasim Sarhan³, Ahmed Salem³, Hamza Ghatasheh ${ }^{3}$, Anoud Alnsour ${ }^{3}$, Zeina Ayoub ${ }^{1}$, Ibrahim Abu Gheida?', Maya Charafeddine ${ }^{1}$, Mohammed Shahait ${ }^{1}$, Ali Shamseddine ${ }^{4}$, Rami Abu Gheida ${ }^{2}$ and Jamal Khader ${ }^{3}$

\begin{abstract}
Background: The aim of this study is to investigate the effect of tumor characteristics and parameters of treatment response in predicting biochemical disease-free survival (BFS) for patients with intermediate or high risk prostate cancer treated by combined definitive external beam radiation therapy (EBRT) and androgen deprivation therapy (ADT).

Methods: Between June 1995 and January 2015, 375 patients with localized prostate cancer and a National Comprehensive Cancer Network (NCCN) intermediate or high risk categories were treated by definitive EBRT and ADT. Median duration of androgen blockade was 10 months (range: 3-36 months); Median radiation dose was 72 Gy (Range: 70-78 Gy). Median follow-up time was 5.8 years (range: 0.8-16.39 years). The main study endpoint was biochemical disease free survival (BFS).
\end{abstract}

Results: Forty seven patients (12.5\%) developed biochemical recurrence (BCR) during the observation period. Monovariate analysis identified baseline PSA (bPSA) $(p=0.024)$, T-stage $(p=0.001)$, Gleason's score (GS) $(p=0.042)$, radiation dose $(p=0.045)$, PSA pre-radiation therapy $(p=0.048)$, and nadir PSA (nPSA), $(p<0.001)$ as significant variables affecting BCR. The receiver operating characteristic (ROC) curve identified a nPSA of $0.06 \mathrm{ng} / \mathrm{ml}$ as optimal cut-off value significantly predicting the patients' risk of BCR $(p<0.001)$. Multivariate cox regression analysis revealed T-stage, GS, and nPSA as independent variable affecting BFS, while bPSA, age, and radiation dose were not.

Conclusion: Nadir PSA at 0.06 is a strong independent predictor of BFS in patients with intermediate or high risk prostate cancer treated by definitive EBRT and ADT.

Keywords: Prostate cancer, External beam radiation therapy, Androgen deprivation, Nadir PSA

\footnotetext{
* Correspondence: fg00@aub.edu.lb

'Department of Radiation Oncology, The Naef K. Basile Cancer Institute at the American University of Beirut Medical Center, Bliss Street, Riad El Solh, Beirut 11072030, Lebanon

Full list of author information is available at the end of the article
} 


\section{Introduction}

Intermediate and high risk localized prostate cancers (PrCa) are effectively treated by definitive external beam radiation therapy (EBRT) in combination with androgen deprivation therapy (ADT). Several large intergroup phase III trials, have demonstrated that the combination of ADT and EBRT lead to a significant improvement in prostate cancer specific mortality (PCSM), distant metastasis, and biochemical recurrence in those patients [1-3]. Prostatespecific antigen (PSA) is an important marker in screening and monitoring prostate cancer patients. It is also a wellestablished prognostic factor in determining the risk of relapse. During the treatment process, baseline PSA (bPSA) typically starts declining indicative of a good response. The lowest PSA levels or nadir (nPSA) is ultimately reached after several weeks or months. The absolute value of nPSA is typically lower and is reached much faster when ADT is added to EBRT [4].

Several studies have analyzed the prognostic value of PSA measurements taken at variable time intervals during and after the course of treatment. These measurements included PSA halving time, PSA post ADT and pre-radiation therapy, PSA immediately post radiation therapy, and nPSA [5-7]. Studies that used nPSA as endpoint have demonstrated that this parameter is an important determinant of outcome that separates patients with good or bad prognosis (below and above the nadir, respectively). However, there is no consensus on the absolute value of nPSA as this parameter's cutoff or assessment method varied widely between studies [4, 8-12]. A probable cause for this variation, could be the composition of the studied patient populations which very often contained a mix of patients treated either by radiation alone or a combination of radiation with or without ADT which could influence the spectrum of PSA response.

The aim of this study is to investigate the effect of nPSA along with other known tumor characteristics such as Tstage, Gleason's score, and bPSA in predicting biochemical disease-free survival (BFS) in intermediate and high risk prostate cancer patients, all being treated with a welldefined protocol of combined EBRT and ADT.

\section{Materials and methods}

This study included two patient populations treated at two institutions in the Middle East: the Naef Basile Cancer Institute (NBCI) at The American University of Beirut, Lebanon and the King Hussein Cancer Center (KHCC) Amman, Jordan. Both institutions are leading academic tertiary referral center for cancer diagnosis and management and have many research and academic programs in common. Between January 1998 and July 2015, a total of 509 Pca patients were seen at both institutions for treatment by definitive radiation therapy. Of those, 375 patients (213 from NBCI and 162 from
KHCC) had a National Comprehensive Cancer Network $(\mathrm{NCCN})$ intermediate or high risk category and were treated with EBRT and concomitant ADT and were retained for this study. The study was approved by the Institutional review boards of both institutions.

The patients' medical records were accessed through the hospital and clinic charts and/or electronic medical records. Data collection included demographic data, baseline tumor characteristics, radiation and hormonal therapy data, toxicity, tumor response parameters, and data on disease recurrence. Patients were stratified into risk groups according to the NCCN criteria for prostate cancer.

Androgen deprivation therapy (ADT) included Luteinizing-Hormone-Releasing Hormone agonist (LHRH) alone or in combination with anti-androgen therapy, for a total duration ranging from 3 to 36 months. A total of 159 patients (42\%) received ADT for less than 6 months, 127 patients (34\%) between 6 and 24 months, and 75 (20\%) patients had more than 24 months. The reason patients received less than 6 months is predominantly because of patient compliance, and more than 24 months is due to physician preference. For 14 patients (4\%) the duration of ADT could not be retrieved. Radiation therapy was delivered by 3D-Conformal Radiation Therapy (3D-CRT) or Intensity-Modulated Radiation Therapy (IMRT) with doses ranging from 70 to $78 \mathrm{~Gy}$. The majority of patients (327 patients; $87 \%$ ) received a dose equal or higher than 72 Gy, whereas 44 patients (12\%) received a dose lower than 72 Gy. Conformal 3DCRT was used for 213 patients (57\%) and IMRT for 160 patients (43\%).

PSA levels after ADT and EBRT were typically obtained every 4 months the first 2 years and every 6 months thereafter. These values were recorded, and the lowest PSA value attained was considered as the nadir PSA. Median Time to nadir was defined as time from end of RT till nadir PSA is achieved. Biochemical recurrence (BCR) was defined as "nPSA $+2 \mathrm{ng} / \mathrm{ml}$ " based on the Phoenix definition [13]. Time to biochemical recurrence was calculated from the time of end of RT till time of recurrence. Median follow-up time from the end of RT for all the patients was 5.8 years $(0.8-16.39)$, [14]. Two hundred seventy patients (73\%) had a minimum follow-up of 3 years.

Biochemical disease free survival rates were estimated using the Kaplan-Meier method and the various groups were compared using the log-rank test. To identify the optimal cutoff for the nadir PSA level, the receiver operating characteristic (ROC) curve was plotted. Equal weight to sensitivity and specificity was given to select the optimal cutoff for patients who had a higher risk of biochemical recurrence. Cox survival analysis was employed for the univariate and multivariate analyses to examine prognostic factors for biochemical recurrence. The included variables were age, bPSA, T-stage, Gleason's 
score, nPSA, radiation dose, ADT duration, PSA preRT, and time to nadir. Using the backward elimination, the hazard ratios (HRs) and 95\% confidence intervals (CIs) were calculated for variables that remained significant in the model. All $p$ values are 2-sided; a value of $p<0.05$ was considered significant. All statistical analysis was performed using the SPSS v.23.0 statistical package.

\section{Results}

\section{Patient characteristics}

Table 1 shows patient demographics and tumor characteristics. Median age was 71 years (range: 51-92 yrs.). The majority of patients had stage T1-T2 disease (261 patients; $70 \%$ ), and $46 \%$ of them had Gleason's score of 7. There was more high risk than intermediate risk patients (62\% vs $38 \%$ respectively). PSA on presentation was almost equally divided between the main risk categories (<10: 32\%; 10-20: 35\%; > 20:32\%).

Table 1 Patient and treatment characteristics

\begin{tabular}{|c|c|c|}
\hline Characteristic & Number & Percent \\
\hline Total & 375 & 100 \\
\hline Median age (yr) & $71(51-92)$ & \\
\hline$\leq 70 \mathrm{yr}$ & 185 & 49.3 \\
\hline$>70 \mathrm{yr}$ & 190 & 50.7 \\
\hline \multicolumn{3}{|l|}{ T stage } \\
\hline $\mathrm{T} 1-\mathrm{T} 2$ & 261 & 69.6 \\
\hline $\mathrm{T} 3-\mathrm{T} 4$ & 103 & 27.5 \\
\hline Unknown & 11 & 2.9 \\
\hline \multicolumn{3}{|l|}{ NCCN risk group } \\
\hline Intermediate & 143 & 38.1 \\
\hline High & 232 & 61.9 \\
\hline \multicolumn{3}{|l|}{ Gleason Score } \\
\hline$<8$ & 241 & 64.3 \\
\hline $8-10$ & 133 & 35.5 \\
\hline Unknown & 1 & 0.3 \\
\hline \multicolumn{3}{|l|}{ PSA on presentation } \\
\hline$\leq 20 \mathrm{ng} / \mathrm{ml}$ & 253 & 67.5 \\
\hline$>20 \mathrm{ng} / \mathrm{ml}$ & 118 & 31.5 \\
\hline Unknown & 4 & 1 \\
\hline Median ADT duration (months) & $10(3-36)$ & - \\
\hline Median Radiation Dose (Gy) & $72(70-78)$ & - \\
\hline$<72$ & 44 & 11.7 \\
\hline$\geq 72$ & 327 & 87.2 \\
\hline Unknown & 4 & 1.1 \\
\hline
\end{tabular}

NCCN National Comprehensive Cancer Network, ADT androgen deprivation therapy, PSA Prostate-Specific Antigen

\section{Patient outcome}

Forty seven patients of the entire group developed biochemical relapse for an estimated 5 and 10-years BFS rates of 88.6 and $66.4 \%$, respectively. Intermediate risk patients had a higher 5 and 10-years BFS rates (95.3 and $79.6 \%$, respectively) compared to high risk patients (84.7 and $58.4 \%$, respectively). This difference between the two risk groups is statistically significant $(p=0.001)$; Fig. 1.

\section{Baseline PSA and nadir PSA}

Intermediate risk patients had a significantly lower PSA on presentation $(10.99 \mathrm{ng} / \mathrm{ml})$ compared to high risk patients $(30.72 \mathrm{ng} / \mathrm{ml}) ;(p<0.001)$. The receiver operating characteristics (ROC) curve revealed an optimal cut-off value for bPSA of $14.55 \mathrm{ng} / \mathrm{mL}$, above which the risk of biochemical recurrence (BCR) increased significantly. BCR developed in $10.2 \%$ of patients with a bPSA $<14.55 \mathrm{ng} / \mathrm{mL}$ compared to $18.4 \%$ of patients with bPSA $\geq 14.55 \mathrm{ng} / \mathrm{mL}(p=0.03)$. In addition, patients with bPSA $<14.55 \mathrm{ng} / \mathrm{mL}$ achieved a lower absolute PSA levels on neoadjuvant ADT alone as noted from pre radiation PSA (preRT PSA) values, $(p<0.001)$, and a lower Nadir PSA $(p=0.019)$ compared to those with bPSA above $14.55 \mathrm{ng} / \mathrm{ml}$. Median nPSA was $0.02 \mathrm{ng} / \mathrm{ml}$. Patients who ultimately developed biochemical recurrence had a higher mean nPSA post RT compared to those patients who had no recurrence $(0.33 \mathrm{ng} / \mathrm{ml}$ vs. $0.07 \mathrm{ng} / \mathrm{ml} ; p<0.001)$. The ROC curve revealed an optimal cut-off value for nPSA of $0.06 \mathrm{ng} / \mathrm{ml}$, with a significant increase in the risk of biochemical recurrence in patients having a nPSA $\geq 0.06 \mathrm{ng} / \mathrm{ml}$. Among patients who had a $\mathrm{nPSA}<0.06 \mathrm{ng} / \mathrm{mL}(n=234$ patients), only 15 patients (6.4\%) developed biochemical recurrence, while 20 out of 78 patients $(25.6 \%)$ with $\mathrm{nPSA} \geq 0.06 \mathrm{ng} / \mathrm{mL}$ developed biochemical relapse $(p<0.001)$. Median Time to nadir was 6 months (range $=0.93-108$ months). In our data set, there was no significant correlation between time to nadir and the risk of biochemical recurrence.

\section{Univariate and multivariate analyses}

Using BFS as endpoint, the following variables were used for univariate analysis: GS, T stage, bPSA, nPSA, pre-RT PSA, radiation dose (RD), age, ADT duration, and time to nadir. GS $(p=0.042)$, T stage $(p=0.001)$, bPSA $(p=0.024)$, nPSA $(p<0.001)$, pre-RT PSA $(p=0.048)$, radiation dose $(p=0.045)$ were significantly associated with BFS, while age, ADT duration, and time to nadir were not (Table 2). Significant variables in the univariate model were then studied in a multivariate cox regression analysis. The model retained T-stage, nPSA, and GS as the only independent variables to significantly affect BFS (Table 3). Patients with stage T1-T2 disease had a BFS at 5- and 10- year of 93 and 74\% respectively compared to 79 and $43 \%$ for those with stage T3-T4 stage disease 


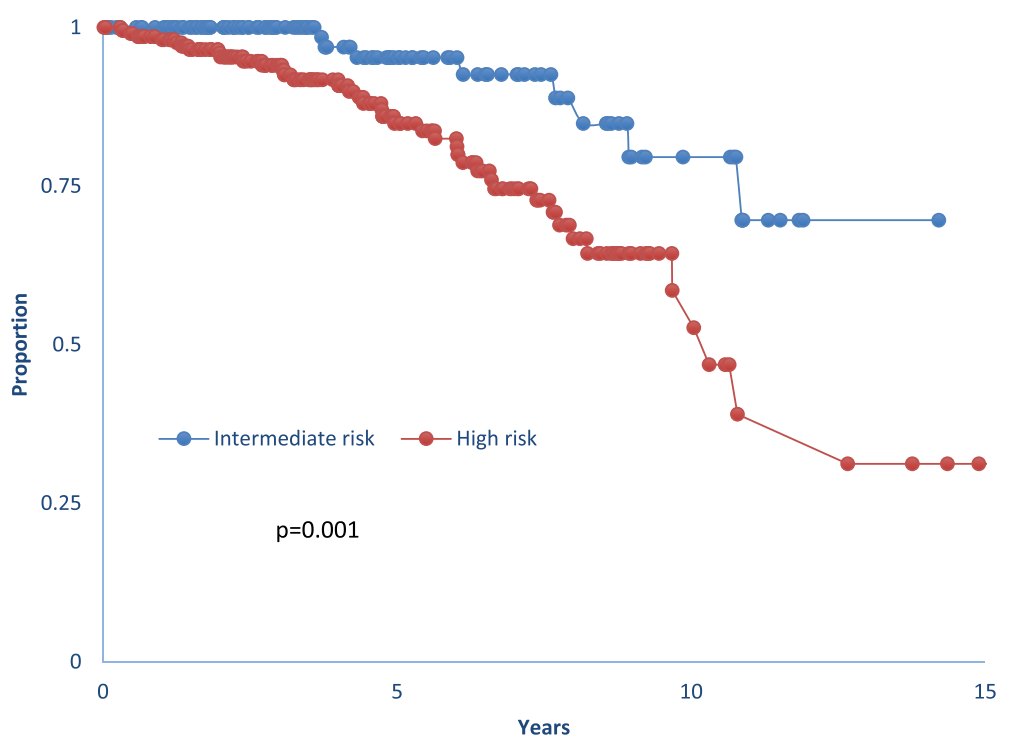

Fig. 1 Kaplan Meier survival curve of biochemical free survival for intermediate and high risk patients. Median survival for high risk patients was 10.3 yrs. Median survival was unreached. For intermediate risk patients

(Fig. 2a). Also patients who had a nPSA below $0.06 \mathrm{ng} / \mathrm{ml}$ had a 5- and 10-year BFS of 96 and $80 \%$, respectively compared to 74 and $53 \%$ for those who had a nadir above the cut-off value of $0.06 \mathrm{ng} / \mathrm{ml}$ (Fig 2b). For GS, the best cutoff grouping was found for grades lower than $8(<8)$ versus GS 8-10; patients with GS $<8$ had a 10-year BFS of $74 \%$ compared to $52 \%$ for those with GS $8-10$ (Fig 2c). Using these three parameters, we then grouped patients

Table 2 Univariate analysis of factors affecting biochemical free survival

\begin{tabular}{lll}
\hline Factor & HR $(95 \% \mathrm{Cl})$ & $p$-value \\
\hline GS & $1.299(1.009-1.672)$ & 0.042 \\
$\quad<8$ & 1 (reference) & - \\
$\quad 8-10$ & $2.007(1.129-3.569)$ & 0.018 \\
bPSA (ng/ml) & $1.009(1.001-1.017)$ & 0.024 \\
$\quad \leq 20 \mathrm{ng} / \mathrm{ml}$ & 1 (reference) & - \\
$>20 \mathrm{ng} / \mathrm{ml}$ & $1.767(0.970-3.218)$ & 0.063 \\
T-stage & $2.226(1.410-3.515)$ & 0.001 \\
T1-T2 & 1 (reference) & - \\
T3-T4 & $3.079(1.691-5.608)$ & $<0.001$ \\
nPSA (ng/ml) & $2.667(1.79-3.973)$ & $<0.001$ \\
$\quad<0.06$ & 1 (reference) & - \\
$\quad \geq 0.06$ & $3.887(1.988-7.599)$ & $<0.001$ \\
RT dose (Gy) & $0.837(0.703-0.996)$ & 0.045 \\
PSA pre-RT (ng/ml) & $1.056(1.0-1.114)$ & 0.048 \\
ADT duration (months) & $0.996(0.970-1.023)$ & 0.784 \\
Age (years) & $0.968(0.926-1.012)$ & 0.148 \\
Time to Nadir (months) & $0.999(0.969-1.031)$ & 0.965 \\
\hline
\end{tabular}

into 3 categories with regard to their risk of BFS: A favorable group with a combination of nPSA $<0.06 \mathrm{ng} / \mathrm{ml}$, T1-T2 stage disease, and GS < 8; an unfavorable group with nPSA $\geq 0.06 \mathrm{ng} / \mathrm{ml}$, T3-T4 stage disease, and GS 810; and an intermediate group containing one unfavorable variable. Five-year BFS rates were $100 \%$ for the favorable group, $87 \%$ for the intermediate, and $31 \%$ for the unfavorable group $(p<0.001)$; (Fig 3$)$.

\section{Discussion}

This study included 375 patients with intermediate or high risk prostate cancers, all treated by combined

Table 3 Multivariate analysis of factors affecting biochemical free survival

\begin{tabular}{cll}
\hline Factor & HR $(95 \% \mathrm{Cl})$ & $p$-value \\
\hline T-stage & $1.84(1.073-3.155)$ & 0.027 \\
T1-T2 & 1 (reference) & - \\
T3-T4 & $2.886(1.408-5.916)$ & 0.004 \\
GS & $1.219(0.887-1.677)$ & 0.222 \\
$<8$ & 1 (reference) & - \\
$8-10$ & $2.449(1.214-4.940)$ & 0.012 \\
nPSA $(\mathrm{ng} / \mathrm{ml})$ & $2.306(1.503-3.537)$ & $<0.001$ \\
$<0.06$ & 1 (reference) & - \\
$\geq 0.06$ & $4.409(2.180-8.916)$ & $<0.001$ \\
bPSA $(\mathrm{ng} / \mathrm{ml})$ & $1.003(0.992-1.014)$ & 0.649 \\
$\leq 20 \mathrm{ng} / \mathrm{ml}$ & 1 (reference) & - \\
$>20 \mathrm{ng} / \mathrm{ml}$ & $1.641(0.765-3.520)$ & 0.203 \\
RT dose $(\mathrm{Gy})$ & $0.916(0.738-1.137)$ & 0.425 \\
\hline
\end{tabular}



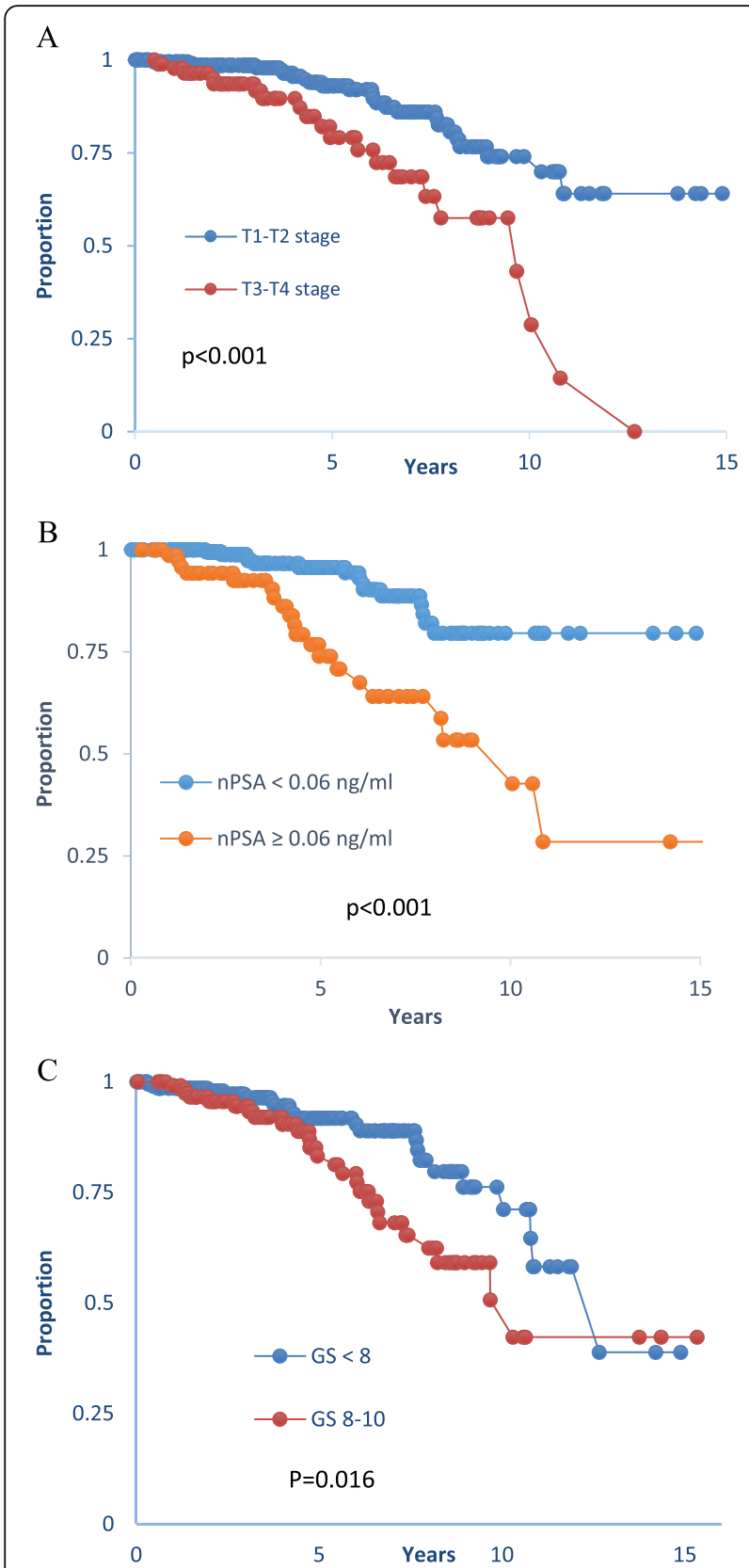

Fig. 2 a Kaplan Meier survival curve of biochemical free survival rates for T1-T2 versus T3-T4 stage. $\mathbf{b}$ Kaplan Meier survival curve of biochemical free survival as a function of nadir PSA (nPSA) with the cutoff of $0.06 \mathrm{ng} / \mathrm{ml}$. c Kaplan Meier survival curve of biochemical free survival rates for patients with Gleason's score (GS) $<8$ and those with GS 8-10

radiation and androgen deprivation therapy. Our main findings were that nadir PSA, along with T-stage, and Gleason's score are the most powerful independent prognostic factors predicting the risk of biochemical recurrence. While T-stage, and GS are well-known and established prognostic factor, which represent tumor characteristics that are known at diagnosis, nPSA is a treatment outcome variable and a less established prognosticator, that is only known after treatment is completed. The optimal cutoff value for nadir PSA was $0.06 \mathrm{ng} / \mathrm{ml}$, above which patients were at an increased risk of BCR. Like many independent variables, when used in combination, patients were better segregated by outcome: favorable with $100 \%$ BFS at 5 years, intermediate with $87 \%$, and unfavorable with $31 \%$ biochemical control at the same time point.

The present study combined two patient populations from two different institutions: NBCI and KHCC. The analysis was first carried on each population separately and the results were found to be very similar with regard to patient characteristics, treatment parameters, and outcome analysis for both univariate and multivariate analyses. The nPSA cutoff value found in our population at the NBCI was $0.056 \mathrm{ng} / \mathrm{ml}$. This nPSAvalue was then tested on the KHCC patient population and was found to be equally significant for BCR, with patients from this group who had a nPSA above 0.056 having a higher rate of biochemical failure than those who had a nPSA below 0.056 (14.7\% vs $3.1 \%$; respectively; $p=0.009)$. When we combined both patient populations, the ROC curve fit identified a slightly higher cutoff value for nPSA, $0.06 \mathrm{ng} / \mathrm{ml}$ (instead of 0.056 ), and this value was retained for the remainder of the analysis.

There are several studies in the literature that examined nPSA as a determinant of outcome in prostate cancer patients treated by definitive radiotherapy with or without ADT $[4,8-12,15,16]$. There are many differences between our study presented here and those studies. These are related to treatment protocols (with or without androgen deprivation) and nPSA cutoff values. The majority of the studies included patients treated either by radiation alone or a mix of radiation alone with or without ADT. Cutoff values for nPSA varied between 0.1 and $0.7 \mathrm{ng} / \mathrm{ml}$ for studies that used nPSA as a continuous or dichotomized variable $[4,11,12,15]$, and between 1.5 and $2 \mathrm{ng} / \mathrm{ml}$ for studies that used a PSA value a fixed time point like 1 or 2 years [8-10]. Some other studies have focused on PSA halving times during the neoadjuvant period before the start of RT $[5,6,17]$. As expected, the addition of androgen blockade to radiation produces more PSA suppression and the studies that included patients treated with ADT have reported lower cutoff values for nPSA $[4,11]$. Tseng and colleagues have looked at nPSA in a mixed population treated by $\mathrm{RT}$ with or without ADT. Those who were treated with combined therapy had a lower nPSA cutoff $(0.1 \mathrm{ng} / \mathrm{ml})$ compared to those treated by RT alone $(0.7 \mathrm{ng} / \mathrm{ml})$ [4]. Similar findings were observed by d'Amico and collaborators in a study combining data from two randomized studies from the USA and Australia [11]. In this particular study, the cutoff of $0.5 \mathrm{ng} / \mathrm{ml}$ was found to be a good separator between good 


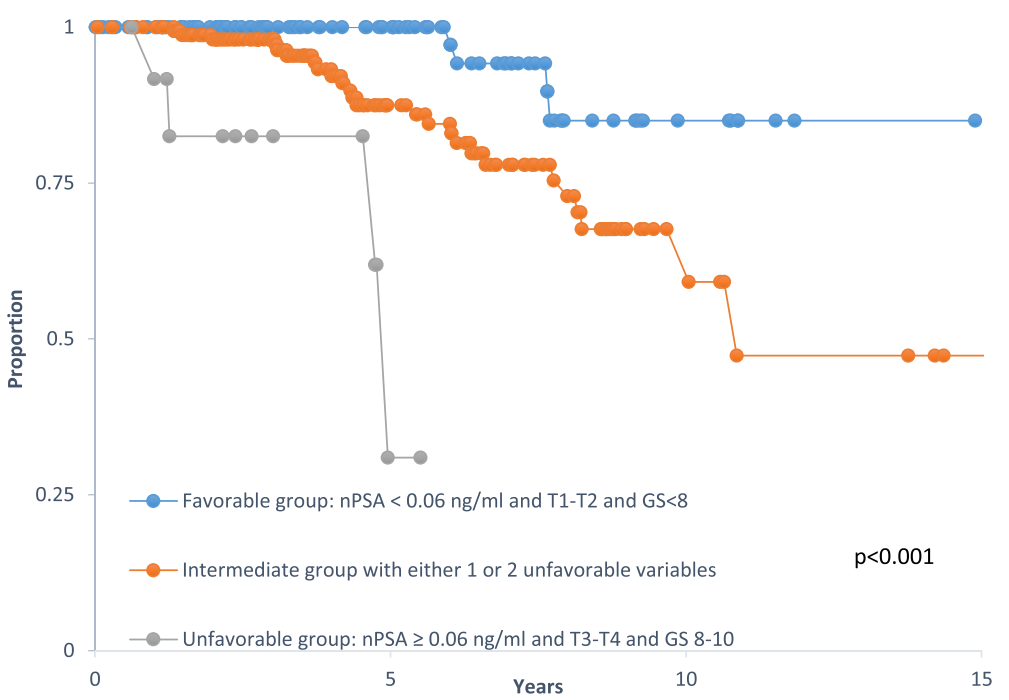

Fig. 3 Kaplan Meier survival curve of biochemical free survival rates by risk categories as a function of nadir PSA (nPSA), T-stage, and Gleason's score (GS)

and poor prognosis patients with regard to prostate cancer specific mortality (PCSM). Moreover, in that study, the authors were able to show that the attaining of the nPSA abolished the benefit of concurrent ADT in that patients who reached a nPSA of $0.5 \mathrm{ng} / \mathrm{ml}$ or lower fared very well regardless if they received concurrent ADT or not. We examined this cutoff value (of $0.5 \mathrm{ng} / \mathrm{ml}$ ) in our dataset and compared it to our cutoff that we determined using the ROC fit $(0.06 \mathrm{ng} / \mathrm{ml})$. Figure 4 shows that both cutoff values $(0.5$ and 0.06$)$ are predictive for BCF in our data. However, the cutoff of 0.06 provided additional prognostic segregation, in that patients who had a nPSA between 0.06 and 0.5 had an intermediate outcome between those with nPSA above 0.5 (unfavorable), and those with nPSA below 0.06 (favorable). This indicates that the cutoff found in our dataset has additional prognostic value and may represent a more powerful predictor at least for the endpoint examined in our study, which is BCF (Table 4). It is of interest to note that Foo and colleagues, who studied a population of predominantly high risk patients treated by combined ADT and radiation therapy, have also found a cutoff value of nPSA similar to ours $(0.06 \mathrm{ng} / \mathrm{ml})$ which was highly predictive of $\mathrm{BF}$ and prostate cancer specific mortality [5].

Other prognostic factors like baseline PSA, preradiation PSA, and radiation dose were examined in our study and they were found all significant in univariate analysis (Table 2). However, none of these factors was

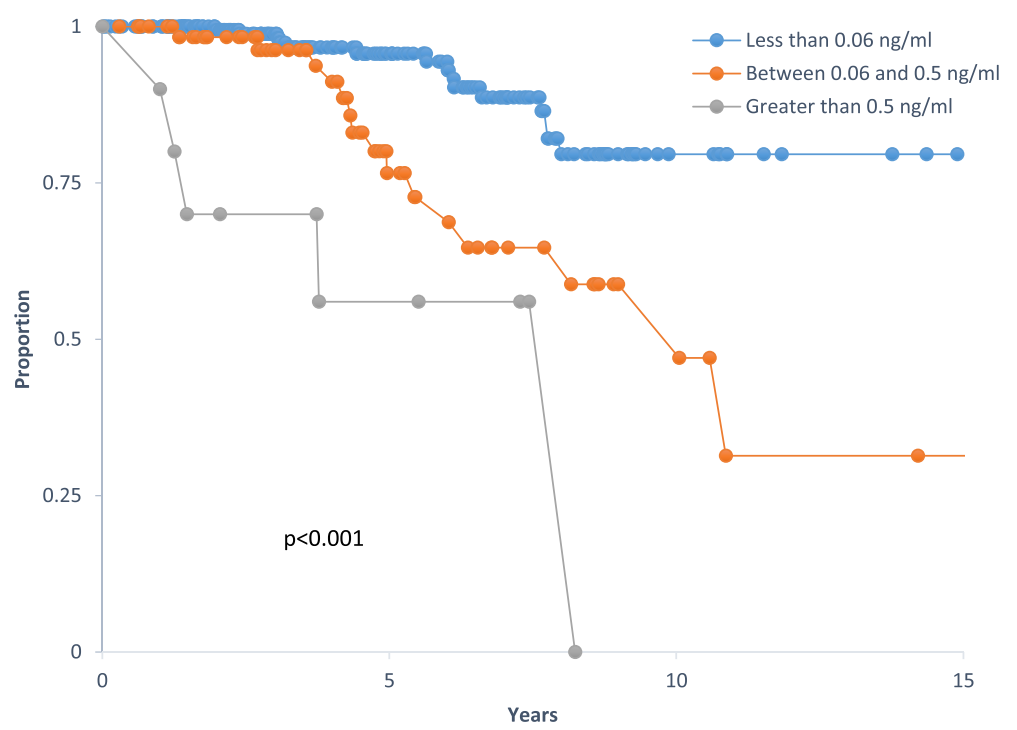

Fig. 4 Kaplan Meier survival curve of biochemical free survival by nadir PSA (nPSA) using two different cutoffs 0.5 and $0.06 \mathrm{ng} / \mathrm{ml} ;(p<0.001)$ 
Table 4 Nadir PSA subgroups and their corresponding 5 and 10-years biochemical free survival

\begin{tabular}{lll}
\hline Subcategories & 5 -years BFS rate $(\%)$ & 10-years BFS rate $(\%)$ \\
\hline nPSA $<0.06$ & 95.7 & 79.6 \\
$0.06<$ nPSA $<0.5$ & 76.6 & 58.8 \\
nPSA $>0.5$ & 56 & 0 \\
\hline
\end{tabular}

retained in the multivariate analysis, when we used the usual stratification by risk category, and the only variables retained were nPSA, GS, and T-stage. It is important to note that time to nadir PSA (tnPSA) was not a significant prognostic factor in both univariate and multivariate analyses, whether it was taken as a continuous or dichotomized variable around the median. It was surprising to see that baseline PSA was not retained by the multivariate analysis as an independent prognostic factor. This is a classic and well established prognostic factor for localized prostate cancer and is a determinant, along with T-stage and GS for the widely used risk categorization of the NCCN [18]. In studies comparable to ours that included nPSA in their analyses, it is not uncommon to see that baseline PSA does not come out as a significant independent variable of outcome $[4,6,10,12,15]$. This may indicate that the prognostic impact of this baseline tumor characteristic is outplayed by treatment response which is represented by nPSA.

Our results also show that radiation dose and preRT PSA value are important factors in determining BCF by univariate analysis. Our median radiation dose was 72 Gy and those patients who received a dose $\geq 72$ Gy fared better. The notion that radiation dose escalation remains effective when patients are treated by combined $\mathrm{RT}$ and ADT has been debated for years. However, recent data confirmed the added benefit of high dose radiation in prostate cancer patients receiving ADT [19-21]. Our results on the dose effect are consistent with these data and suggest keeping high radiation doses for patients receiving ADT. Regarding preRT PSA, several studies have demonstrated the predictive value of this parameter. Large single institution and intergroup database have been retrospectively queried and demonstrated that a preRT PSA below the range of $0.3-0.5 \mathrm{ng} / \mathrm{ml}$ is predictive of a good outcome [5, 17, 22-24]. In our study, preRT PSA was recorded in 294 out of the 375 patients; 133 of them (45\%) reached a preRT PSA $\leq 0.5 \mathrm{ng} / \mathrm{mL}$ and achieved a 5 -years BFS rate of $90 \%$ compared to $85 \%$ for those who had a preRT PSA $>0.5 \mathrm{ng} / \mathrm{ml}(p=0.04)$. Similar results were obtained when using a PreRT PSA cutoff of $0.3 \mathrm{ng} / \mathrm{ml}(\mathrm{p}=0.04)$. Unfortunately, because of missing data for 81 patients, this parameter could not be used in the multivariate analysis.

\section{Conclusion}

In conclusion, our study here has examined the effect of nPSA on biochemical failure for patients with NCCN intermediate and high risk prostate cancer treated by combined androgen ablation and definitive radiation therapy. Along with T-stage, and Gleason's score, nadir PSA of $0.06 \mathrm{ng} / \mathrm{ml}$ was found to be a strong independent predictor of BCF. All three parameters could be used to improve our prognostic classification for those patients and might help initiate early and more individualized therapy, such as second line hormonal ablation or chemotherapy, when there is a high predicted risk of recurrence.

\section{Acknowledgements}

Not applicable.

Funding

Not applicable.

\section{Availability of data and materials}

The datasets used and/or analyzed during the current study are available from the corresponding author on reasonable request.

\section{Summary}

Three hundred and seventy five patients with intermediate or high risk localized prostate cancer were treated by definitive radiation therapy and androgen deprivation therapy (ADT). Baseline PSA, T-stage, Gleason's score, radiation dose, PSA pre-radiation therapy, and nadir PSA (nPSA) were found significant variables affecting biochemical relapse (BCR) in univariate analysis. Time to nadir was not significant. However, only nPSA with a cutoff at $0.06 \mathrm{ng} / \mathrm{ml}$, T-stage, and Gleason's score were found to be independent predictors of BCR.

\section{Authors' contributions}

FG participated in designing the study, data analysis, and writing the final manuscript. MB, RK, AAM, NS, AS, HG, AA, AS, and JK contributed to patient treatment, analysis, and review of the manuscript. TYA, ZA, IAG, and MC participated in data collection, data analysis and in reviewing the final manuscript. MA, MS, and RAG participated in data collection and data entry. TYA and MC performed the statistical analysis. All authors read and approved the final manuscript.

\section{Authors' information}

Not applicable.

Ethics approval and consent to participate

All procedures performed in studies involving human participants were in accordance with the ethical standards of the Institutional Review Board (IRB) and with the 1964 Helsinki declaration and its later amendments or comparable ethical standards. Informed consent was obtained from all individual participants included in the study.

\section{Consent for publication}

Not applicable.

\section{Competing interests}

The authors declare that they have no competing interests.

\section{Publisher's Note}

Springer Nature remains neutral with regard to jurisdictional claims in published maps and institutional affiliations.

\section{Author details}

${ }^{1}$ Department of Radiation Oncology, The Naef K. Basile Cancer Institute at the American University of Beirut Medical Center, Bliss Street, Riad El Solh, Beirut 11072030, Lebanon. ${ }^{2}$ Division of Urology, the American University of 
Beirut Medical Center, Beirut, Lebanon. ${ }^{3}$ Department of Radiation Oncology, King Hussein Cancer Center, Amman, Jordan. ${ }^{4}$ Division of Medical Oncology, The Naef K. Basile Cancer Institute at the American University of Beirut Medical Center, Beirut, Lebanon.

Received: 1 June 2017 Accepted: 1 September 2017

Published online: 07 September 2017

\section{References}

1. Roach M 3rd, Bae K, Speight J, et al. Short-term neoadjuvant androgen deprivation therapy and external-beam radiotherapy for locally advanced prostate cancer: long-term results of RTOG 8610. J Clin Oncol. 2008;26:585-91.

2. D'Amico AV, Manola J, Loffredo M, et al. Six-month androgen suppression plus radiation therapy vs radiation therapy alone for patients with clinically localized prostate cancer: a randomized controlled trial. JAMA. 2004:292:821-7.

3. Bolla M, Van Tienhoven G, Warde P, et al. External irradiation with or without long-term androgen suppression for prostate cancer with high metastatic risk: 10-year results of an EORTC randomized study. Lancet Oncol. 2010;11:1066-73.

4. Tseng YD, Chen M, Beard C, Martin N, Orio PF, Loffredo M, et al. Posttreatment prostate specific antigen nadir predicts prostate cancer specific and all-cause mortality. J Urol. 2012;187(6):2068-73.

5. Foo M, Lavieri M, Pickles T. Impact of neoadjuvant prostate-specific antigen kinetics on biochemical failure and prostate cancer mortality: results from a prospective patient database. Int J Radiat Oncol Biol Phys. 2013;85(2):385-92.

6. Malik R, Jani AB, Liauw SL. Prostate-specific antigen halving time while on neoadjuvant androgen deprivation therapy is associated with biochemical control in men treated with radiation therapy for localized prostate cancer. Int J Radiat Oncol Biol Phys. 2011;79(4):1022-8.

7. Lee WR, Hanlon AL, Hanks GE. Prostate specific antigen nadir following external beam radiation therapy for clinically localized prostate cancer. J Urol. 1996:156 (2):450-3.

8. Ray ME, Thames HD, Levy LB, Horwitz EM, Kupelian PA, Martinez AA, Kuban DA. PSA nadir predicts biochemical and distant failures after external beam radiotherapy for prostate cancer: a multi-institutional analysis. Int J Radiat Oncol Biol Phys. 2006;64(4):1140-50.

9. Alcántara P, Hanlon A, Buyyounouski MK, Horwitz EM, Pollack A Prostate-specific antigen nadir within 12 months of prostate cancer radiotherapy predicts metastasis and death. Cancer. 2007;109(1):41-7.

10. Zelefsky MJ, Shi W, Yamada Y, Kollmeier MA, Cox B, Park J, Seshan VE. Postradiotherapy 2-year prostate-specific antigen nadir as a predictor of long-term prostate cancer mortality. Int J Radiat Oncol Biol Phys. 2009;75(5):1350-6.

11. D'amico AV, Chen M, Castro MD, Loffredo M, Lamb DS, Steigler A, Denham JW. Surrogate endpoints for prostate cancer-specific mortality after radiotherapy and androgen suppression therapy in men with localised or locally advanced prostate cancer: an analysis of two randomised trials. Lancet Oncol. 2012;13(2):189-95.

12. Son CH, Hamstra DA, Feng FY, Liauw SL. High-risk prostate cancer treated with dose-escalated RT: an analysis of hormonal therapy use and duration, and prognostic implications of PSA nadir 0.2 to select men for short-term hormonal therapy. Am J Clin Oncol. 2014:40(4):348-52.

13. Roach M 3rd, Hanks G, Thames H Jr, et al. Defining biochemical failure following radiotherapy with or without hormonal therapy in men with clinically localized prostate cancer: recommendations of the RTOG-ASTRO Phoenix Consensus Conference. Int J Radiat Oncol Biol Phys. 2006;65:965-74.

14. Cox JD, Stetz J, Pajak TF. Toxicity criteria of the Radiation Therapy Oncology Group (RTOG) and the European Organization for Research and Treatment of Cancer (EORTC). Int J Radiat Oncol Biol Phys. 1995;31(5):1341-6.

15. Johnson SB, Jackson WC, Murgic J, Feng FY, Hamstra DA. Time to nadir PSA: of popes and PSA-the immortality bias. Am J Clin Oncol. 2015;38(5):465-71.

16. Critz FA, Levinson AK, Williams WH, Holladay DA, Holladay CT. The PSA nadir that indicates potential cure after radiotherapy for prostate cancer Urology. 1997:49(3):322-6.

17. Cury FL, Hunt D, Roach M 3rd, Shipley W, Gore E, Hsu IC, et al. Prostatespecific antigen response after short-term hormone therapy plus external-beam radiotherapy and outcome in patients treated on Radiation Therapy Oncology Group study 9413. Cancer. 2013;119(11):1999-2004.

18. Mohler JL, Armstrong AJ, Bahnson RR et al. Prostate cancer, version 1.2016. J Natl Compr Cancer Netw. 2016;14(1):19-30.
19. Dubray BM, Beckendorf V, Guerif S, Le Prise E, Reynaud-Bougnoux A, Hannoun Levi JM, et al. Does short-term androgen depletion add to high-dose radiotherapy (80 Gy) in localized intermediate-risk prostate cancerintermediary analysis of GETUG 14 randomized trial (EU-20503/NCT00104741). J Clin Oncol. 2011;29(suppl; abstr):4521. 2011 ASCO Annual Meeting.

20. Nabid A, Carrier N, Vigneault E, Souhami L, Lemaire C, Brassard M, et al. Place of short-term androgen deprivation therapy in intermediate-risk prostate cancer treated with radiotherapy: a phase III trial. J Clin Oncol. 2015;33(suppl 7; abstr):5. 2015 Genitourinary Cancers Symposium

21. Bolla M, Maingon P, Carrie C, Villa S, Kitsios P, Poortmans P, et al. Short androgen suppression and radiation dose escalation for intermediate- and high-risk localized prostate cancer: results of EORTC trial 22991. J Clin Oncol. 2016:34:1748-56. doi:10.1200/JCO.2015.64.8055.

22. Zelefsky MJ, Gomez DR, Polkinghorn WR, Pei X, Kollmeier M. Biochemical response to androgen deprivation therapy before external beam radiation therapy predicts long-term prostate cancer survival outcomes. Int J Radiat Oncol Biol Phys. 2013:86(3):529-33.

23. Zilli T, Dal Pra A, Kountouri M, Miralbell R. Prognostic value of biochemical response to neoadjuvant androgen deprivation before external beam radiotherapy for prostate cancer: a systematic review of the literature. Cancer Treat Rev. 2016;46:35-41.

24. McGuire SE, Lee AK, Cerne JZ, Munsell MF, Levy LB, Kudchadker RJ, et al. PSA response to neoadjuvant androgen deprivation therapy is a strong independent predictor of survival in high-risk prostate cancer in the dose- escalated radiation therapy era. Int J Radiat Oncol Biol Phys. 2013;85(1):e39-46.

\section{Submit your next manuscript to BioMed Central and we will help you at every step:}

- We accept pre-submission inquiries

- Our selector tool helps you to find the most relevant journal

- We provide round the clock customer support

- Convenient online submission

- Thorough peer review

- Inclusion in PubMed and all major indexing services

- Maximum visibility for your research

Submit your manuscript at www.biomedcentral.com/submit
) Biomed Central 